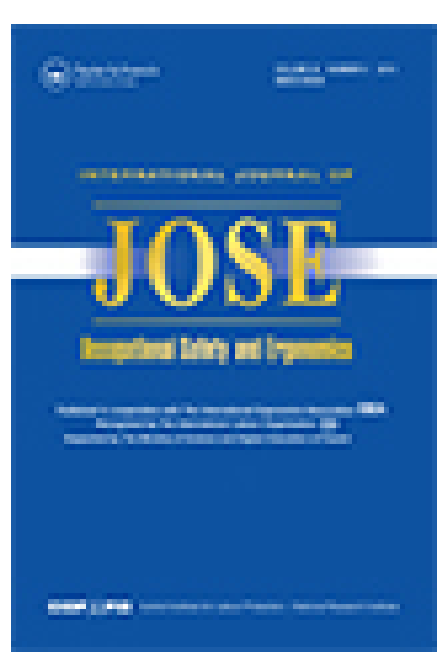

International J ournal of Occupational Safety and Ergonomics

Publication details, including instructions for authors and subscription information:

http:// www.tandfonline.com/loi/ tose20

\title{
A Prescriptive Exercise Program for Health Maintenance
}

Akiko Yamashita $^{a}$, Mitsuyuki Kawakami ${ }^{b}$, Yoshimasa Inagaki ${ }^{b} \&$ Takao Ohkubo $^{c}$

a Kanagawa University, J apan

${ }^{\mathrm{b}}$ Tokyo Metropolitan Institute of Technology, J apan

c Nihon University, J apan

Published online: $08 \mathrm{~J}$ an 2015.

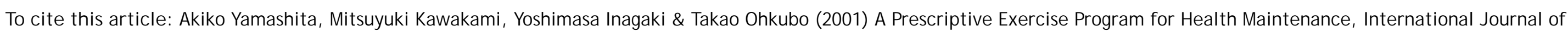
Occupational Safety and Ergonomics, 7:2, 195-209

To link to this article: http:// dx.doi.org/ 10.1080/10803548.2001.11076486

\section{PLEASE SCROLL DOWN FOR ARTICLE}

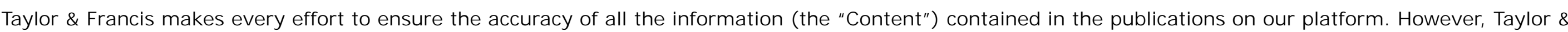

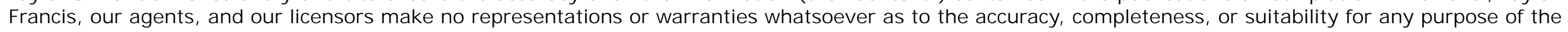

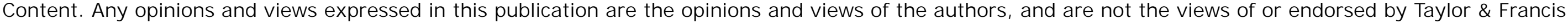

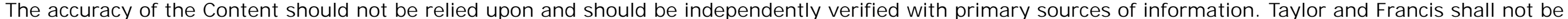

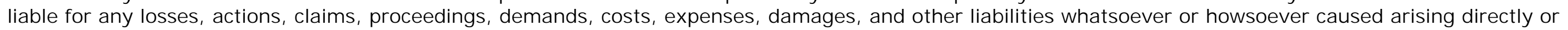
indirectly in connection with, in relation to or arising out of the use of the Content.

This article may be used for research, teaching, and private study purposes. Any substantial or systematic reproduction, redistribution, reselling, loan, sublicensing, systematic supply, or distribution in any form to anyone is expressly forbidden. Terms \& Conditions of access and use can be found at http:// www.tandfonline.com/page/terms-and-conditions 


\title{
A Prescriptive Exercise Program for Health Maintenance
}

\author{
Akiko Yamashita \\ Kanagawa University, Japan \\ Mitsuyuki Kawakami \\ Yoshimasa Inagaki \\ Tokyo Metropolitan Institute of Technology, Japan

\section{Takao Ohkubo}

\section{Nihon University, Japan}

\begin{abstract}
The aim of this study was to design a prescriptive exercise program for people of various age and fitness basing on the popular in Japan Radio Physical Fitness Exercise, a program based on an experimental approach. The evaluation indices used in the experiment were heart rate $(\mathrm{HR})$, oxygen consumption, and electrical activity of the rectus femoris, latissimus dorsi, and trapezius muscles, which measured during various motion elements of the program performed at various rate. The results of this study enable to calculate equations for predicting HR during exercise from relative metabolic rate (RMR). The data on HR, RMR, and myoelectric potential presented in this study may be a basis for designing individual exercise programs for elderly people.
\end{abstract}

health maintenance prescriptive exercise program aging society heart rate relative metabolic rate myoelectric potential

Correspondence and requests for reprints should be sent to Mitsuyuki Kawakami, Tokyo Metropolitan Institute of Technology, Asahigaoka 6-6, Hino, J-191 Tokyo, Japan. E-mail: $<$ kawakami@tmit.ac.jp >. 


\section{INTRODUCTION}

In 1995, the National Institute of Population and Social Security Research reported that the average lifespan of the Japanese male was 76.36 years and that of the Japanese female 82.84 years. These data showed an extended life span by 1.41 years for men and by 2.09 years for woman in comparison with the 1985 statistics. If this tendency continues, in only 24 years Japan will become an aged society compared to Western countries. In Japan, the population of people aged 65 years or older will reach $25.2 \%$. Therefore one of the important problems is and will continue to be the maintenance of personal health of aging people. As the length of life after retirement continues to increase, the lifestyle of the elderly living at home tends to limit their physical activity. Although a number of people exercise in sports clubs or local gymnasiums, poor accessibility and high cost limit the possibility of elderly people to actively participate in such programs. Therefore, an exercise program appropriate for various age groups, from the young to the advanced, needs to be prescribed and be accessible to the population as a whole. It is also well-known that random exercise done by older people without concern for their current state of health can be dangerous and can often have adverse effects (Cooper, 1963, 1970; Hettinger, Brikhead, Horvath, Issekutz, \& Rodahl, 1961; Maeda \& Usami, 1989; Robinson, 1938; Yamashita, Kawakami, Ukai, \& Ohkubo, 1988). These issues show the need for not only a prescriptive exercise program but also for a formula for prescribing particular exercises for the elderly (Yamashita Kawakami, Inagaki, Ukai, \& Ohkubo, 1997). This paper presents a proposal for designing an exercise program for health maintenance based on the motion elements of the Japanese Radio Physical Fitness Exercise. The results also provide a formula for calculating the effects of exercises so that effective yet safe exercises can be prescribed.

\section{METHOD}

The Radio Physical Fitness Exercise (13 postures) was chosen as the subject of study because it is well-known and one of the most popular fitness exercise programs in Japan. The research method included an analysis of the structural content, intensity, and kind of motion elements in the Fitness Program (Table 1 and Figure 1). The influence of exercises on the physiological functions was determined and indices used in the experiment were 
obtained by measuring heart rate (HR), integrated electromyograms registered at 5-s intervals (later referred to as myoelectric potential), and oxygen intake.

\section{TABLE 1. Motion Elements of Radio Physical Fitness Exercise}

\begin{tabular}{lcc}
\hline Motion Element & Engaged Parts of Body & Engaged Joints \\
\hline (1) & arms, shoulders, legs & shoulders, ankles \\
(2) (12) & arms, shoulders, knees & shoulders, elbows, knees, ankles \\
(3) & arms, shoulders, chest & shoulders \\
(4) & arms, shoulders & shoulders, elbows \\
(5) & arms, shoulders, back, sides, loins & shoulders \\
(6) & back, loins & - \\
(7) & arms, shoulders, back, loins & - \\
(8) & arms, shoulders, legs & shoulders, elbows, ankles \\
(9) & shoulders, back, chest, loins & shoulders \\
(10) & back, loins & shoulders \\
(11) & arms, shoulders, legs & shoulders, loins, ankles \\
(13) & arms, shoulders & shoulders \\
\hline
\end{tabular}

The participants were 21 healthy women (ranging in age from 31 to 58 years) who participated in Experiments I and II. The data were taken over a period of 2 months. In Experiment III the participants were 11 healthy males (ages 21 to 25 years), and data were collected over a period of 1 month. Both groups were familiar with the basic exercise program and all tests were done in a controlled environment at a temperature of $26{ }^{\circ} \mathrm{C}$ and a humidity of $60 \%$.

The measurements of heart rate, myoelectric potential, and metabolic rate were taken with 4-channel memory equipment produced by VINE Co., Japan.

The study was composed of three experiments. In Experiment I relative metabolic rate $(\mathrm{RMR})$ and heart rate $\left(\mathrm{HR}_{\text {submax }}\right)$ of participants were measured during each of the 13 postures of the program (see Table 1 and Figure 1). Experiment II was designed to provide data on the differences in RMR and HR related to the rate (Conditions A, B, C) of each motion element. In Experiment III RMR was measured through exercises performed with the use of the upper or lower half of the body. By developing a formula for the upper and lower half of the body and the whole body, prescriptive exercises could be developed for each person depending on his or her exercise ability. The experimental conditions for Experiment I, II, and III are shown in Table 2 and the gauging points for measuring the myoelectric potential are 
TABLE 2. Contents of Experiment

\begin{tabular}{|c|c|}
\hline $\begin{array}{l}\text { Motions } \\
\text { and } \\
\text { motion } \\
\text { speed }\end{array}$ & 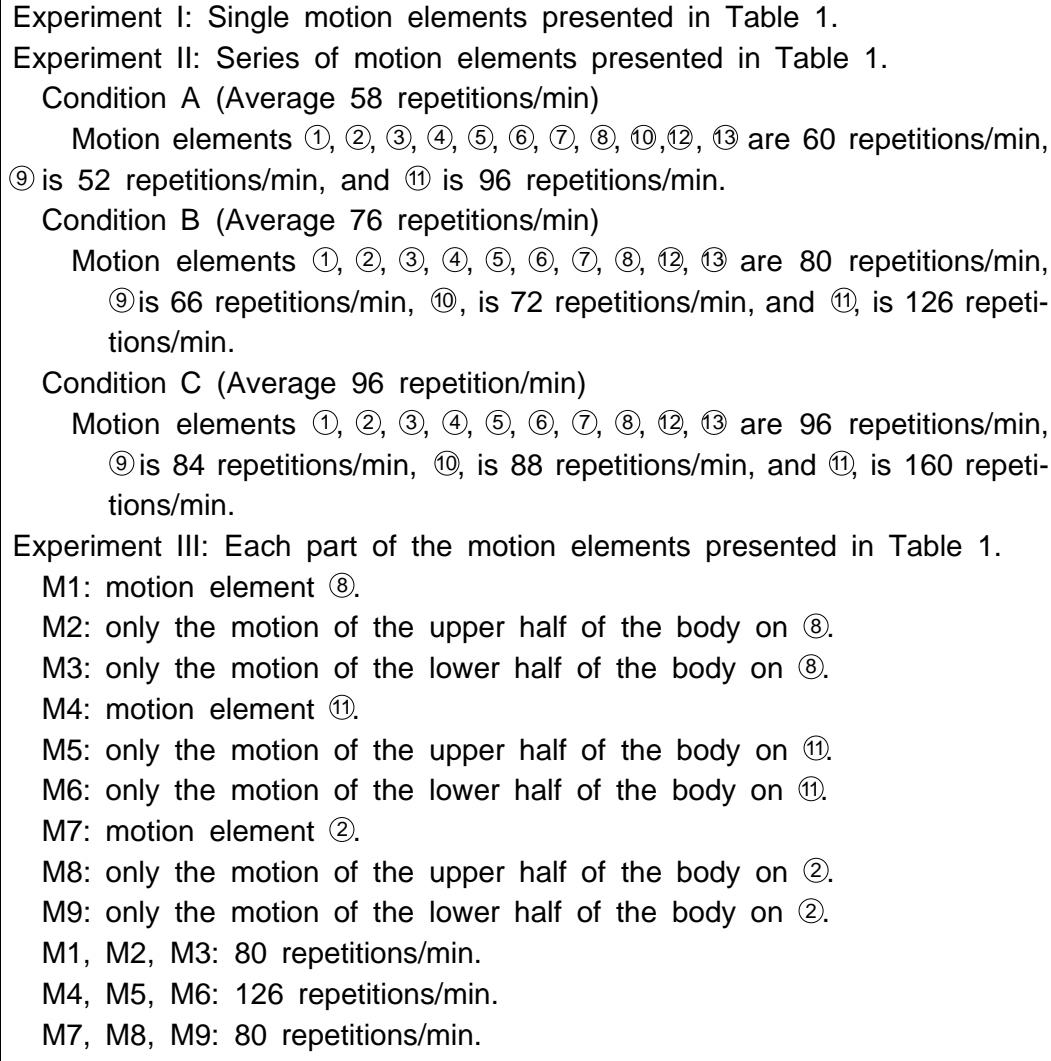 \\
\hline $\begin{array}{l}\text { Evaluated } \\
\text { indices }\end{array}$ & $\begin{array}{l}\text { Evaluated indices are change of oxygen intake, functions of the heart and } \\
\text { lungs (HR averaged for 5-s intervals), and muscle function (myoelectric } \\
\text { potentials of surface electrodes [vitrode-S] were placed in pairs with } 30-\mathrm{mm} \\
\text { center distance upon carefully prepared skin covering the muscles studied, } \\
\text { which were trapezius, latissimus dorsi, and rectus femoris muscle). }\end{array}$ \\
\hline Participants & $\begin{array}{l}\text { Experiment I and Experiment II: } 21 \text { healthy women randomly selected. } \\
\text { Age: } 31-58 \text { years (Average } 46.6 \text { years } \pm 8.7 \text { ) } \\
\text { Height: } 143-159 \mathrm{~cm} \text { (Average } 153.3 \mathrm{~cm} \pm 4.6 \text { ). } \\
\text { Weight: } 41-72 \mathrm{~kg} \text { (Average } 53.0 \mathrm{~kg} \pm 7.6 \text { ). } \\
\text { Experiment: } 11 \text { healthy men randomly selected. } \\
\text { Age: } 21-25 \text { years (Average } 22.5 \text { years } \pm 1.4 \text { ) } \\
\text { Height: } 163-172 \mathrm{~cm} \text { (Average } 168.2 \mathrm{~cm} \pm 3.1 \text { ). } \\
\text { Weight: } 58-72 \mathrm{~kg} \text { (Average } 65.5 \mathrm{~kg} \pm 4.4)\end{array}$ \\
\hline $\begin{array}{c}\text { Other } \\
\text { conditions }\end{array}$ & $\begin{array}{l}\text { The experiments were performed inside a room (average temperature: } 26{ }^{\circ} \mathrm{C} \text {, } \\
\text { average humidity: } 60 \% \text { ). Participants were well practiced in the experimental } \\
\text { motions. }\end{array}$ \\
\hline
\end{tabular}

Notes. (1) ... (13)—cf. Table 1 and Figure 1. 


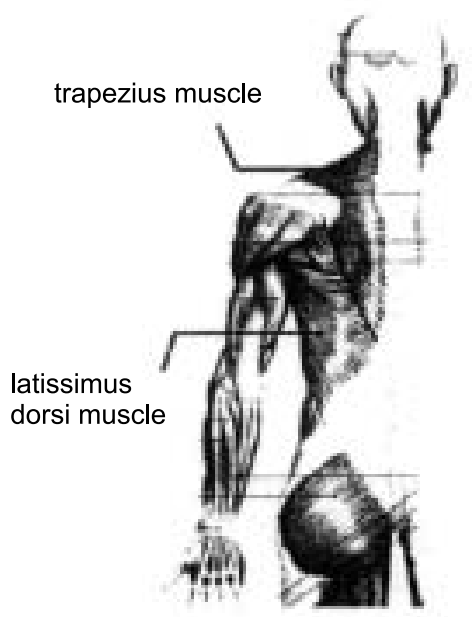

Back (upper half of the body)

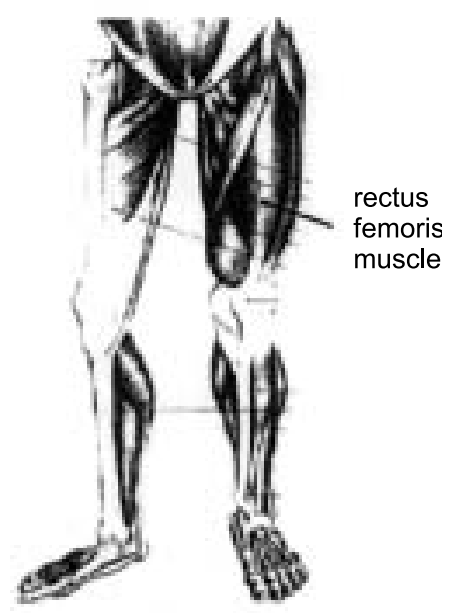

Front (lower half of the body)

Figure 2. Gauging points of myoelectric potential.

\section{RESULTS AND DISCUSSION}

\subsection{Experiment I and II}

Figure 3 shows the results of RMR calculated from oxygen intake. It is clear that the RMRs of (2), (11) and (12) motion elements, which engage the lower half of the body, are relatively large. Generally, RMR increases with motion speed, except for motion element (11), that is, high jumping when RMR is the largest during condition A. An analysis of variance showed that RMR is significantly influenced by the mode of exercise and its speed

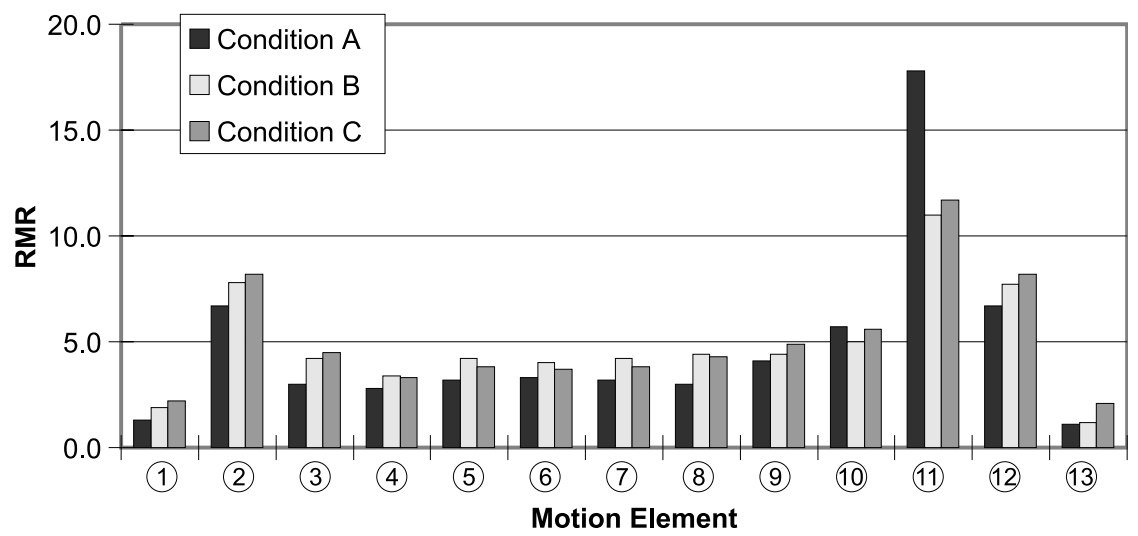

Figure 3. Relative metabolic rate (RMR) on each motion element. 
$(p<.01)$. Moreover, the contribution of the motion element to the total RMR variability is $71.5 \%$. Therefore, the motion element composition is an important factor of exercise intensity.

Figure 4 shows the results of the submaximal heart rate $\left(\mathrm{HR}_{\text {submax }}\right)$ measurement during a stationary state for each motion element. As the pattern of $\mathrm{HR}_{\text {submax }}$ was similar to that of RMR, it is concluded that $\mathrm{HR}$ can be used for the evaluation of exercise intensity.

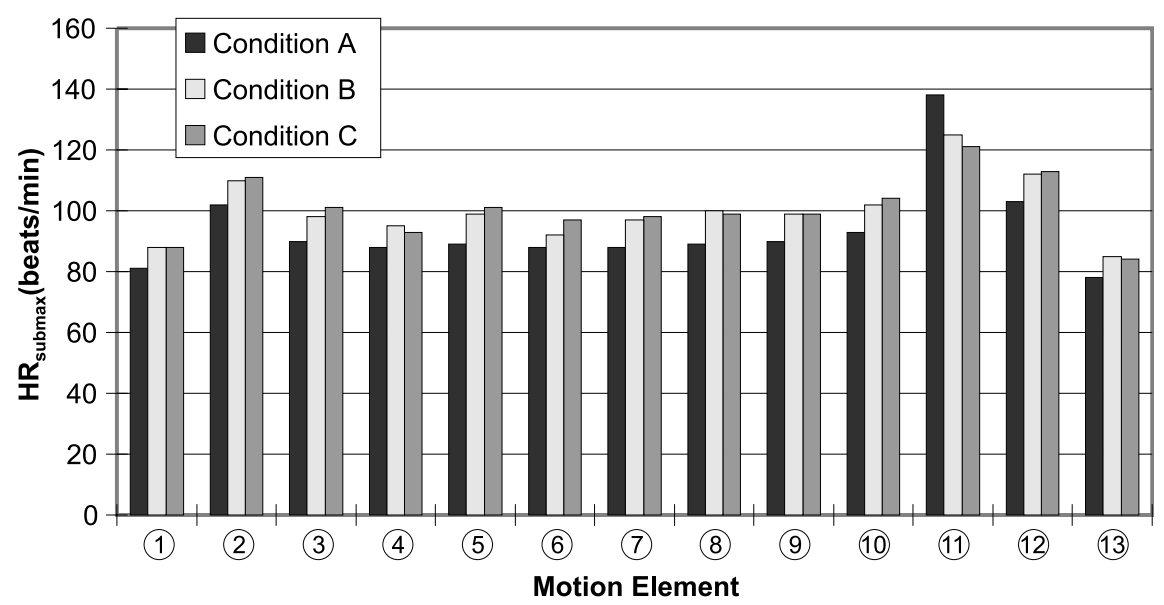

Figure 4. Heart rate $\left(\mathbf{H R}_{\text {submax }}\right)$ on each motion element.

The analysis of variance showed a significant influence $(p<.01)$ of motion speed on myoelectric potential. The contribution of speed to the total variability was $42.2 \%$ in the trapezius muscle, $17.7 \%$ in latissimus dorsi, and $45.0 \%$ in the rectus femoris muscle. These results are based on the intensity (RMR) of motion elements (2), (11) and (12). Therefore these motion elements may induce functional muscle improvement (Yamashita, Kawakami, Echizenya, \& Ukai, 1995).

The results of RMR calculated from oxygen intake at each condition are presented in Figure 5. As can be seen, RMR increases with motion speed. The participants performed the Radio Physical Fitness Exercise under condition B every day for 2 months in order to estimate the training effect. As it is shown in Figure 6, the resting metabolism increased progressively with training time. A two-way (training time and participants) analysis of variance (ANOVA) showed a significant effect of the training on the resting oxygen consumption $(p<.01)$. Moreover, a significant difference was found between the resting metabolic rate before and after 2 months of training $(p<.01)$. The results confirmed those of Hori (1991), showing high 
metabolic rates in trained participants. The results of Yamashita et al. (1995) showed the Radio Physical Fitness Exercise under condition B to be intensive enough to improve the functions of the heart and lungs even for elderly people.

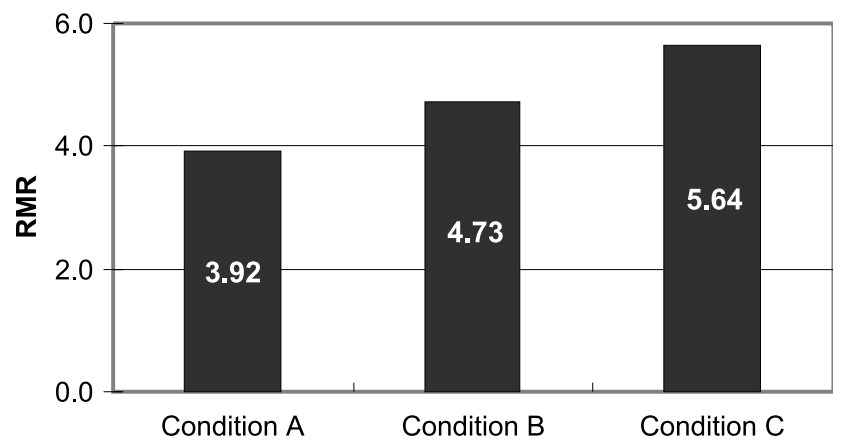

Figure 5. Relative metabolic rate (RMR) of Radio Physical Fitness Exercise performed at various rates.

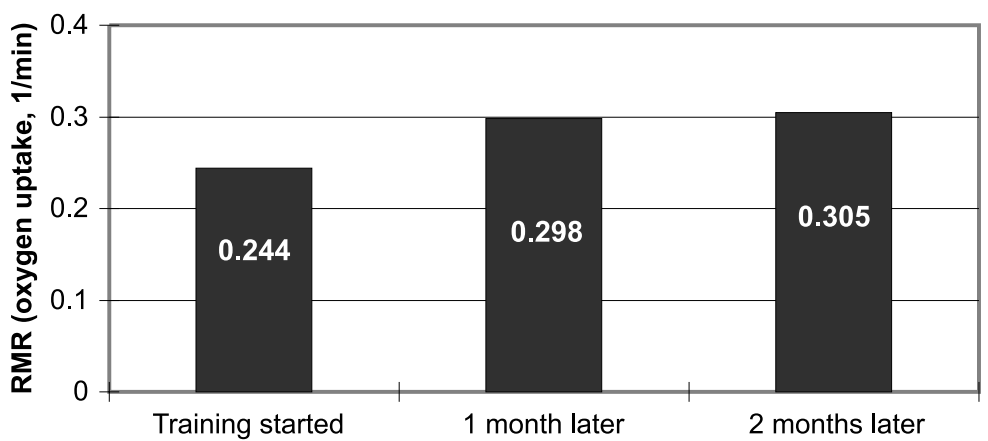

Figure 6. Effect of training on resting metabolic rate.

\subsection{Experiment III}

Table 3 presents a comparison of myoelectric potential of the rectus femoris muscle between motion elements. By using a $t$ test significant differences $(p<.05)$ were found between the motion of the whole body and the motion of the lower half of the body except for motion element (11). It appeared that the motion of the upper half of the body, (motion elements (2) and (8) has a large effect on the myoelectric potential of the rectus femoris muscle.

The results of $\mathrm{HR}_{\text {submax }}$ in Experiment III are presented in Figure 7. As can be seen, the $\mathrm{HR}_{\text {submax }}$ was lowest during the motion of the upper half of the body, and highest during exercises engaging the whole body musculature 
TABLE 3. $t$ Test (Myoelectric Potential of Rectus Femoris Muscle)

\begin{tabular}{llll}
\hline Motion & $\varphi$ & $\boldsymbol{t}_{0}$ Value & Test \\
\hline M1 $\times$ M2 & 8 & $3.89^{* *}$ & reject \\
M1 $\times$ M3 & $\mathbf{8}$ & $\mathbf{2 . 7 5 ^ { \star }}$ & reject \\
M2 $\times$ M3 & 8 & $3.85^{* *}$ & reject \\
M4 $\times$ M5 & 8 & $4.97^{* *}$ & reject \\
M4 $\times$ M6 & $\mathbf{8}$ & $\mathbf{0 . 4 4}$ & accept \\
M5 $\times$ M6 & 8 & $4.48^{* *}$ & reject \\
M7 $\times$ M8 & 7 & $2.66^{*}$ & reject \\
M7 $\times$ M9 & 7 & $3.65^{\star *}$ & reject \\
M8 $\times$ M9 & 7 & $2.97^{\star *}$ & reject \\
\hline
\end{tabular}

Notes. ${ }^{* *}$-difference at a $1 \%$ significant level, *-difference at a $5 \%$ significant level, $\varphi$-degree of freedom, M1 ... M9—cf. Table 2.

except for motion element 8. Table 4 summarizes the results of a three-way ANOVA (A: elements of exercise, B: kinds of exercises, C: participants) performed in order to detect factors that influence $\mathrm{HR}_{\text {submax }}$. The data showed that $\mathrm{HR}_{\text {submax }}$ depended on each factor. Specifically, the contribution of the elements of the exercises was $29.3 \%$, and that of the kinds of exercises was $29.5 \%$.

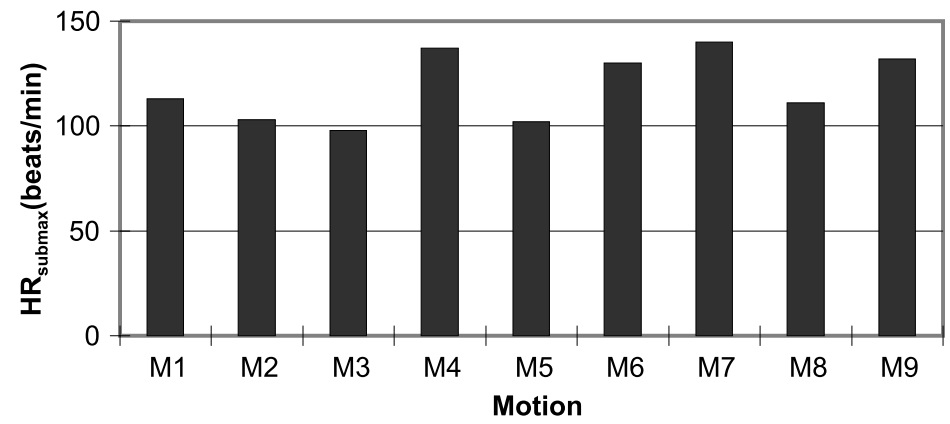

Figure 7. Heart rate $\left(\mathrm{HR}_{\text {submax }}\right)$ on each motion (Experiment III).

Figure 8 shows the results of RMR in Experiment III. As can be seen, RMR was increasing with an increase of the muscle engaged. It was lowest during the motion of the upper half of the body, and greatest during exercises engaging the whole body musculature. Table 5 shows a comparison of RMR during whole body exercises and the value obtained by adding RMR during upper and lower half of the body exercises. As it is shown, significant differences were found during motion elements (2) and (8). Considering RMR as energy expended during $1 \mathrm{~min}$ (Asahino, 1981), the motion of the 
TABLE 4. Three-Way ANOVA ( HR $\left._{\text {submax }}\right)$

\begin{tabular}{lrrrrr}
\hline Factor & $\boldsymbol{S S}$ & $\boldsymbol{\varphi}$ & $\mathbf{V}$ & $\boldsymbol{F}_{\mathbf{0}}$ value & \multicolumn{1}{c}{$\rho$} \\
\hline $\mathrm{A}$ & 6969 & 2 & 3684.0 & & 29.3 \\
$\mathrm{~B}$ & 7016 & 2 & 3508.0 & $175.3^{* *}$ & 29.5 \\
$\mathrm{C}$ & 3894 & 8 & 486.8 & $176.5^{* *}$ & 15.8 \\
$\mathrm{~A} \times \mathrm{B}$ & 3052 & 4 & 763.0 & $24.5^{\star *}$ & 12.6 \\
$\mathrm{~A} \times \mathrm{C}$ & 1152 & 16 & 72.0 & $38.4^{* *}$ & 3.5 \\
$\mathrm{~B} \times \mathrm{C}$ & 930 & 16 & 58.1 & $3.6^{* *}$ & 2.6 \\
$e$ & 636 & 32 & 19.9 & $2.9^{* *}$ & 6.7 \\
$T$ & 23648 & 80 & & & 100.0 \\
\hline
\end{tabular}

Notes. ${ }^{* *}$ - difference at a $1 \%$ significant level, $\mathrm{HR}_{\text {submax }}$-heart rate, $\varphi$ - degree of freedom, $\mathrm{V}$-variance, $\rho$-contribution rate, A-elements of exercise, B-kinds of exercises, $\mathrm{C}$-participants.

whole body is smoother than individual motions of (2) and (8) So, in order to show the relation of RMR during whole body exercise $\left(\mathrm{RMR}_{\mathrm{w}}\right)$, upper half body exercise $\left(R M R_{U}\right)$, and lower half body exercise $\left(R M R_{L}\right)$, the following formula was suggested:

$$
\mathrm{RMR}_{\mathrm{W}}=\alpha \times\left(\mathrm{RMR}_{\mathrm{U}}+\mathrm{RMR}_{\mathrm{L}}\right) .
$$

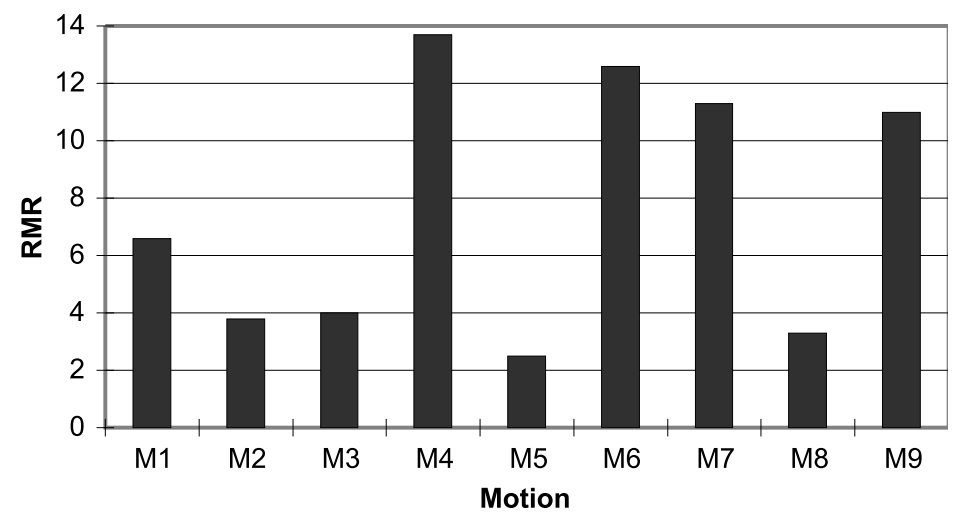

Figure 8. Relative metabolic rate (RMR) on each motion (Experiment III).

Coefficients $\alpha$, obtained by the least squares method, are shown in Table 6. The following results can be seen from Table 6 and Table 3 (myoelectric potential of rectus femoris muscle): During motion elements (2) and (8), exercise engaging the upper half of the body markedly affects the myoelectric potential of the rectus femoris muscle, subsequently, the value of $\alpha$ becomes low. On the other hand, during motion element (1) its effect is less pronounced and $\alpha$ becomes larger. 
TABLE 5. $t$ Test (Relative Metabolic Rate [RMR] of the Whole Body and a Value That Added 2 RMRs)

\begin{tabular}{llll}
\hline Motion Element & $\varphi$ & $\boldsymbol{t}_{0}$ Value & Test \\
\hline (8) & 9 & $4.26^{* *}$ & reject \\
$(11)$ & 8 & 1.97 & accept \\
$(2)$ & 6 & $4.03^{* *}$ & reject \\
\hline
\end{tabular}

Notes. ${ }^{* *}$ - difference at a $1 \%$ significant level, $\varphi$-degree of freedom, (8), (11), (2)—cf.

Table 1 and Figure 1.

TABLE 6. Comparison of Table 3 and $\alpha$ Calculated From Each Data

\begin{tabular}{lcc}
\hline Motion Element & Coefficient $\alpha$ & $\boldsymbol{t}$ Test from Table 3 \\
\hline (2) & .79 & $3.65^{\star *}$ \\
$(8)$ & .86 & $2.75^{\star}$ \\
$(11)$ & .92 & 0.44 \\
\hline
\end{tabular}

Notes. ${ }^{* *}$-difference at a $1 \%$ significant level, *-difference at a 5\% significant level, (2), (8), (11)-cf. Table 1 and Figure 1.

Regression lines 3, 4, and 5 of Figures 9, 10, and 11 were calculated in order to show the relation between RMR and $\mathrm{HR}_{\text {submax }}$ on each part of the exercise:

$\mathrm{HR}_{\text {submax }}($ whole body $)=78.15+4.67 \times \mathrm{RMR}$,

$\mathrm{HR}_{\text {submax }}$ (upper half of the body) $=78.09+8.29 \times \mathrm{RMR}$,

$\mathrm{HR}_{\text {submax }}$ (lower half of the body) $=76.38+4.60 \times \mathrm{RMR}$.

According to Karvonen, Kentla, and Mustal (1957), target heart rate (THR) can be calculated from formula 6 using $\alpha$ (changing the coefficient for physical capacity), $\mathrm{HR}_{\max }$, and $\mathrm{HR}_{\text {rest }}$ :

$$
\mathrm{THR}=\mathrm{HR}_{\mathrm{rest}}+\alpha \times\left(\mathrm{HR}_{\max }-\mathrm{HR}_{\mathrm{rest}}\right) .
$$

$\mathrm{HR}_{\text {max }}$ is given by formula 7 (Kattus, 1972):

$$
\mathrm{HR}_{\text {max }}=(220-\text { age }) .
$$

Formula 8 can be calculated by inserting formula 7 into formula 6 :

$$
\mathrm{THR}=(1-\alpha) \times \mathrm{HR}_{\text {rest }}+\mathrm{a} \times(220-\text { age }) .
$$




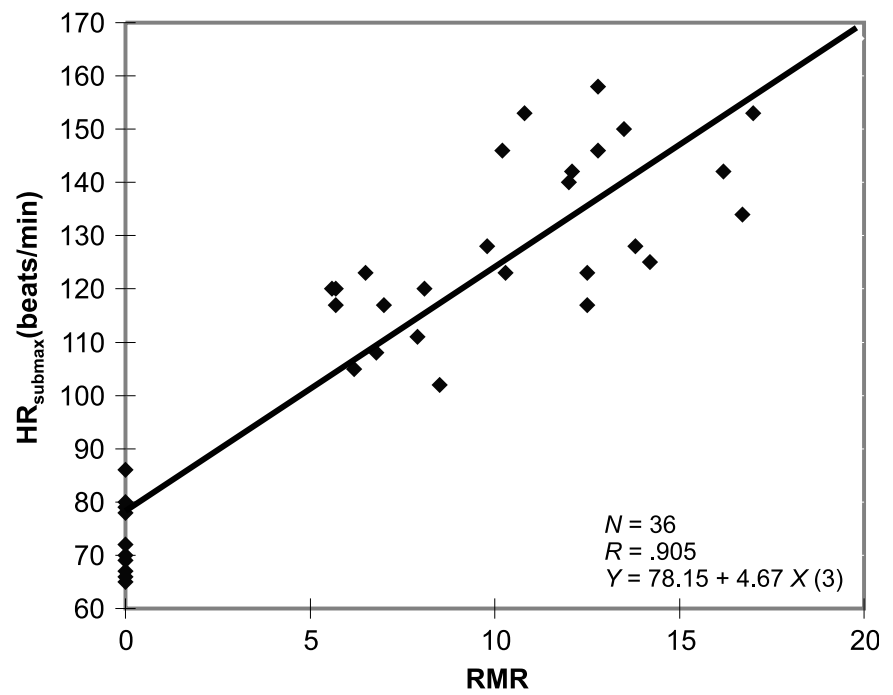

Figure 9. Relation between relative metabolic rate $(\mathrm{RMR})$ and heart rate $\left(\mathbf{H R}_{\text {submax }}\right.$, whole body).

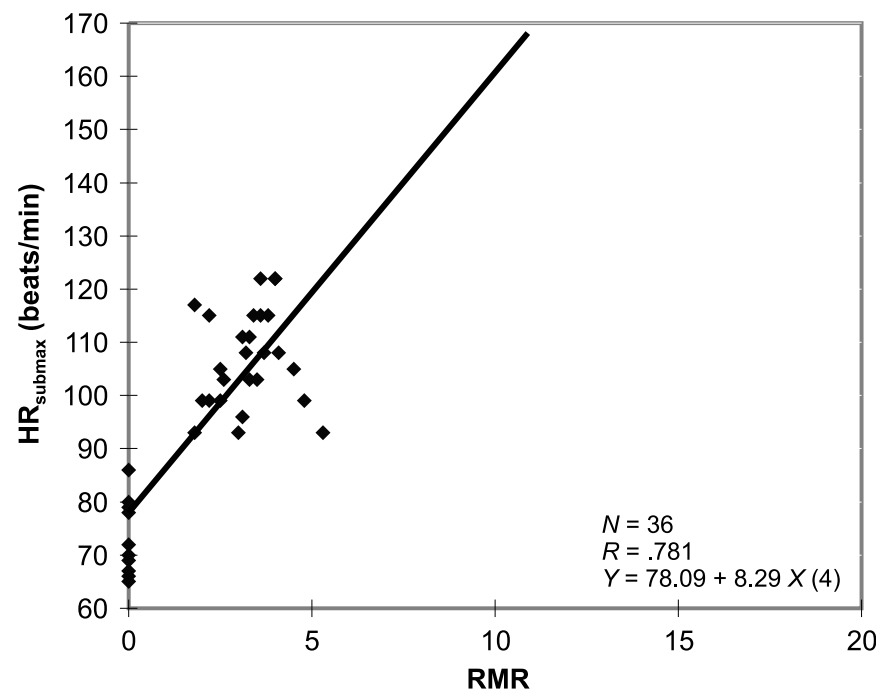

Figure 10. Relation between relative metabolic rate (RMR) and heart rate ( $\mathbf{H R}_{\text {submax, }}$ upper half of the body).

Therefore, by substituting average $\mathrm{HR}_{\text {rest }}(72.9$ beats/min) and average age (22.5 years old) of the participants into formula 8 , the resulting THRs are 135.2 beats/min $(\alpha=.5), 147.7$ beats/min $(\alpha=.6)$ and 160.2 beats/min $(\alpha=.7)$, respectively. Table 7 is RMR and a $2 \sigma$ confidence for THR for each part of the exercises. At first sight, it was thought that exercises of the upper half of the body were suitable for the improvement of the functions of the heart and lungs. The upper limit of $\mathrm{HR}_{\text {submax }}$ is about 120 beats/min 


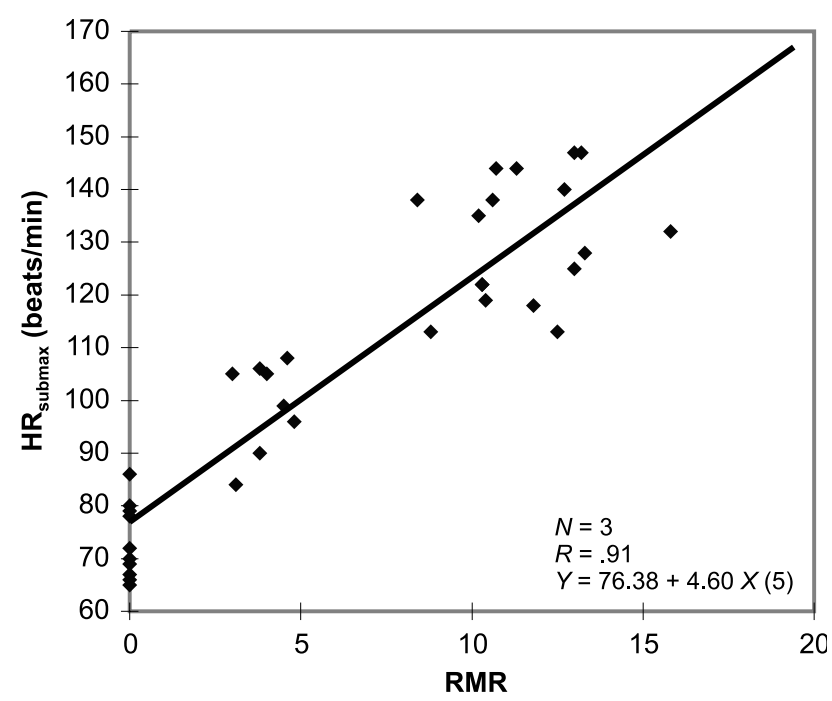

Figure 11. Relation between relative metabolic rate (RMR) and heart rate $\left(\mathbf{H R}_{\text {submax, }}\right.$ lower half of the body).

for the upper half of the body only. But 130 beats/min of $H_{\text {submax }}$ is needed for prescriptive exercise programs if the goal is to improve heart and lung functions in healthy participants (Yamashita et al., 1995).

TABLE 7. Relative Metabolic Rate (RMR) Corresponding to Each Target Heart Rate (THR)

\begin{tabular}{lccc}
\hline Parts of Exercise & $\begin{array}{c}\mathbf{5 0 \%} \text { THR }(\alpha=\mathbf{5}) \\
\mathbf{1 3 5 . 2 0} \text { beats/min }\end{array}$ & $\begin{array}{c}\mathbf{6 0 \%} \text { THR }(\alpha=\mathbf{6}) \\
\mathbf{1 4 7 . 7 0} \text { beats/min }\end{array}$ & $\begin{array}{c}\mathbf{7 0 \%} \text { THR }(\alpha=\mathbf{7}) \\
\mathbf{1 6 0 . 2 0} \text { beats } / \mathbf{m i n}\end{array}$ \\
\hline \multirow{2}{*}{ Whole body } & $12.22 \pm 5.28$ & $14.89 \pm 5.28$ & $17.57 \pm 5.28$ \\
Upper half of the body & $(6.94,17.50)$ & $(9.61,20.17)$ & $(12.29,22.85)$ \\
& $(4.89 \pm 2.52$ & $8.40 \pm 2.52$ & $9.90 \pm 2.52$ \\
Lower half of the body & $12.79 \pm 4.57)$ & $(5.88,10.92)$ & $(7.39,12.42)$ \\
& $(8.22,17.36)$ & $15.50 \pm 4.47$ & $18.22 \pm 4.57$ \\
& & $(10.93,20.07)$ & $(13.65,22.79)$ \\
\hline
\end{tabular}

\section{CONCLUSIONS}

The design factors for a prescriptive exercise program for health maintenance have been proposed and various exercise combinations, their intensity, and the kind of motion elements involved have been discussed. The results indicate that 
1. for the functional improvement of muscles, the characteristics of the motion elements is of significant importance;

2. condition B (average of 76 repetitions per minute) was intensive enough for the enhancement of the resting metabolic rate;

3. the motion elements of the upper half of the body had a high effect on the myoelectric potential of the leg muscles (rectus femoris muscle);

4. primary factors affecting $\mathrm{HR}_{\text {submax }}$ were the kind of exercise and the rate of performance;

5. an experimental formula, which shows the relation between RMR and $\mathrm{HR}_{\text {submax }}$ for different motion elements of each exercise, has been proposed.

Though exercise programs and health maintenance are common topics when discussing the elderly, there are few studies that provide an objective way to prescribe or design a health maintenance program to fit the particular needs or health conditions of each person. This becomes more of an issue for the elderly, where health, health maintenance, and fitness are more crucial to their quality of life. Whereas this study has limitations, it was done as a step to providing a beginning for research in this particular field.

\section{REFERENCES}

Asahino, K. (1981). Physical and exercise. Tokyo, Japan: Taisyukan-shoten. (In Japanese). Cooper, K.H. (1963). Aerobics. New York, NY, USA: Evans.

Cooper, K.H. (1970). The new aerobics. New York, NY, USA: Evans.

Hettinger, R., Brikhead, N.C., Horvath, S.M., Issekutz, B., Jr., \& Rodahl, K. (1961). Assessment of physical work capacity. Journal of Applied Physiology, 16, 153-159. Hori, S. (1991). Physical function and exercise. Tokyo, Japan: Kinpodo. (In Japanese). Karvonen, M.J., Kentla, E., \& Mustal, D. (1957). The effects of training on heart rate. Annual Medicine Experimental Biological, Fennoscandia, 35, 307-315.

Kattus, A.A. (1972). Exercise testing and training of apparently healthy individuals: A handbook for physicians. Dallas, TX, USA: American Heart Association.

Maeda, K., \& Usami, M. (1989). Clinical sports cardiology. Tokyo, Japan: Asakura-shoten. (In Japanese).

National Institute of Population and Social Security Research. (1995). An estimation of future population of Japan. Tokyo, Japan: Welfare Ministry of Japan. (In Japanese).

Ohshima, M., \& Ohkubo, T. (1993). Human engineering. Tokyo, Japan: Asakura-shoten. (In Japanese).

Robinson, S. (1938). Experimental studies of physical fitness in relation to age. Arbeitsphysiologie, 10, 251-323. 
Yamashita, A., Kawakami, M., Echizenya, K., \& Ukai, T. (1995). Motion elements and suitable prescriptive exercises for health care. The 73rd Japan Society of Mechanical Engineers Fall Annual Meeting, Tokyo, 4, 66-67. (In Japanese).

Yamashita, A., Kawakami, M., Inagaki, Y., Ukai, T., \& Ohkubo, T. (1997). A suitable prescriptive exercise program for health maintenance. In P. Seppälä, T. Luopajärvi, C.-H. Nygård, \& M. Mattila (Eds.), Proceedings of the 13th Triennial Congress of the International Ergonomics Association, Tampere, Finland, 1997 (Vol. 5, pp. 633-635). Helsinki, Finland: Finnish Institute of Occupational Health.

Yamashita, A., Kawakami, M., Ukai, T., \& Ohkubo, T. (1988). A suitable prescriptive exercise program of health maintenance for aged persons, ergonomic practice and its theory. The 5th Pan-Pacific Conference on Occupational Ergonomics, 14-16. 